\title{
Diagnóstico de resistência do Mycobacterium tuberculosis à rifampicina utilizando-se da reação em cadeia da polimerase
}

\author{
Wânia da Silva Carvalho*1, Silvana Spíndola de Miranda², Jorge Luiz Pesquero ${ }^{3,4}$, \\ Maria Aparecida Gomes ${ }^{3}$
}

${ }^{1}$ Departamento de Farmácia Social, Faculdade de Farmácia, Universidade Federal de Minas Gerais, ${ }^{2}$ Departamento de Clínica Médica/Pneumologia, Faculdade de Medicina, Universidade Federal de Minas Gerais, ${ }^{3}$ Instituto de

Ciências Biológicas, Universidade Federal de Minas Gerais, ${ }^{4}$ Universidade de Mogi das Cruzes

*Correspondência:

W.S.Carvalho

Departamento de Farmácia Social,

Faculdade de Farmácia

Universidade Federal de Minas Gerais

Av. Antônio Carlos, 6.627, sala 1060,

$1^{\circ}$ andar, Campus Pampulha

31270-910 - Belo Horizonte - MG,

Brasil

E-mail: wscarv@icb.ufmg.br
A resistência do Mycobacterium tuberculosis aos tuberculostáticos tem surgido como grande ameaça à Saúde Pública. A resistência à rifampicina pode ser considerada como um marcador para a multi-resistência a fármacos e tem sido atribuída a mudanças estruturais da RNA polimerase, produto de expressão do gene rpoB. Os pacientes portadores dessas cepas têm baixa perspectiva frente ao tratamento. Os testes convencionais de sensibilidade aos fármacos realizados em cultura do Mtb requerem várias semanas para o crescimento. Por este motivo, a Reação em Cadeia da Polimerase (PCR), método de baixo custo e que pode reduzir o tempo para o diagnóstico, representa alternativa viável e promissora. Neste artigo estão descritos os métodos mais comumente empregados na detecção de mutantes resistentes à rifampicina baseados na PCR, como análise de Polimorfismo Conformacional de Fita Simples (Single-Strand Conformation Polymorphism, SSCP), PCR Heteroduplex e INNO-LIPA. Recentemente, padronizou-se a técnica de PCR em baixa estringência, usando um único iniciador (Low Stringency Single Specific Primer, LSSP), que se mostrou um método rápido e sensivel na detecção de mutações no gene rpoB.

\author{
Unitermos \\ - Mycobacterium \\ tuberculosis \\ - Resistência \\ - Rifampicina \\ - PCR
}

\section{INTRODUÇÃO}

A tuberculose (TB) é uma doença antiga e possui distribuição mundial. De acordo com a Organização Mundial de Saúde (WHO, 2005), 80\% dos casos novos (8,7 milhões) estão distribuídos em 22 países do mundo e o Brasil ocupa o $15^{\circ}$ lugar. Entre 2000 e 2020, 1 bilhão de pessoas serão infectadas, 200 milhões irão adoecer e 35 milhões morrerão se não for melhorado o controle.

A TB está intimamente relacionada ao empobrecimento de grande parte da população mundial, ao advento da infecção pelo vírus da imunodeficiência humana (HIV), aos movimentos migratórios internos e externos, ao envelhecimento da população mundial, à alta taxa de abando- 
no do tratamento, ao aparecimento da resistência aos tuberculostáticos e reduzido interesse da comunidade científica e dos formadores de políticas públicas.

Em um inquérito mundial realizado de 1994 a 1999 sobre resistência do Mycobacterium tuberculosis (Mtb), foi verificado que dos 72 países que participaram do inquérito, 63 concentravam cepas multi-resistentes a fármacos (MDR). Em um inquérito feito no Brasil de 1996 a 1997, $31 \%$ das cepas do Mtb eram resistentes aos principais medicamentos utilizados no tratamento da tuberculose: rifampicina, isoniazida, etambutol e estreptomicina, (Brasil, 2002). O surgimento de cepas MDR tem chamado a atenção e levado muitos pesquisadores a investigar os mecanismos que provocam essa resistência e desenvolver métodos para a detecção dos fatores que podem conferir resistência aos principais tuberculostáticos (Snider, Roper, 1992; Friden et al., 1993; Iseman, 1994; Williams et al., 1994; Cooksey et al., 1997; Telenti et al., 1997; Watterson et al., 1998; Carvalho et al., 2003). É bem conhecido que os métodos convencionais para testar a sensibilidade aos tuberculostáticos tais como teste de sensibilidade em meio de Loweinstein-Jensen (4 a 8 semanas), Sistema BACTEC, MGIT (Tubo Indicador de Crescimento de Micobactéria), MB/Bact (7 a 10 dias) são demorados, exceto quando se utilizam o método com bacteriófago, E-test e Citometria de Fluxo (Wilson et al., 1997; Kirk et al., 1998; Riska et al., 1999; Tortoli et al., 1999; Brunello et al., 2000; Kakkar et al., 2000; Bemer et al., 2002; Krishnamurthy et al., 2002; Katoch, 2004). Entre as várias técnicas moleculares atualmente aplicadas ao estudo de mutações destacam-se as baseadas na PCR, dentre elas o Polimorfismo Conformacional de Fita Simples (Single-Strand Conformation Polymorphism, SSCP), a análise de PCR Heteroduplex, ensaios com sondas de DNA(INNO-LIPA), o seqüenciamento de DNA e outras que representam variantes da PCR. Recentemente, a técnica de PCR na qual se usa um único iniciador em condições de baixa estringência (LSSP) (Pena et al., 1994) foi utilizada para detectar mutações no gene rpoB de amostras provenientes de pacientes com TB e de cultura do Mycobacterium tuberculosis resistentes ou não a rifampicina (Carvalho et al., 2003). O método mostrou-se promissor na detecção rápida dessas mutações nesse gene.

\section{RESISTÊNCIA À RIFAMPICINA}

A rifampicina (Figura 1) foi descoberta em 1957, a partir do cultivo de uma cepa de Streptomyces, que foi denominada Streptomyces mediterranei, isolada pela primeira vez em 1963 (Rieder, 2002).

A rifampicina foi introduzida na terapia da tubercu-

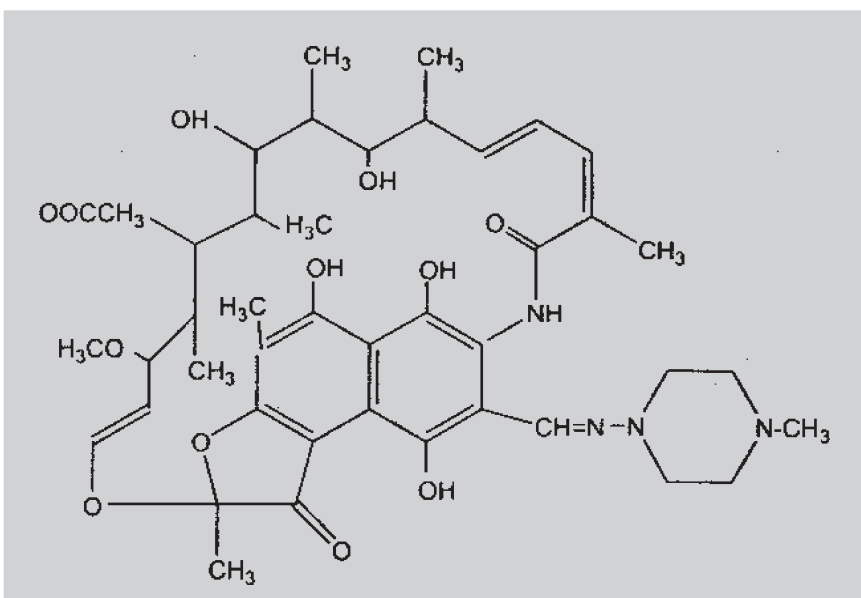

FIGURA 1 - Estrutura da rifampicina, isolada e semisintetizada por Maggi et al. (1966).

lose no início da década de 1970. É extremamente efetiva contra o M. tuberculosis, sendo um antibiótico de amplo espectro de ação. A Concentração Inibitória Mínima (CIM) da rifampicina, 0,25 a $0,5 \mathrm{mg} / \mathrm{mL}$ em meio líquido, foi definida como a mais baixa entre os fármacos que inibem o crescimento do Mtb (Lee, Heifets, 1987; Murray et al., 1990; Roberts et al., 1991; Taniguchi et al., 1996). A rifampicina é a "chave" do esquema terapêutico, sendo que alguns autores chamam a atenção para o fato de que pacientes portadores de cepas de $M$. tuberculosis resistentes à rifampicina têm grande chance de serem resistentes a outros tuberculostáticos (Mitchison, Nunn, 1986; Fischl et al., 1992). Nesse contexto, a resistência à rifampicina pode ser considerada como um marcador para MDR e pacientes que desenvolvem resistência a esse medicamento têm baixa perspectiva frente ao tratamento, necessitando utilizar medicamentos de segunda linha como alternativa (Iseman, 1993; Drobniewski, 1997). Esses possuem maior toxicidade, elevam o custo, tornam necessário o aumento do tempo de tratamento e levam a menor adesão.

A resistência à rifampicina, um dos principais fármacos utilizados no tratamento da $\mathrm{TB}$, com ação intra e extracelular (Fiúza de Melo, 1997), ocorre devido a mutação no gene $r p o B$, que codifica para a cadeia beta da RNA polimerase, local de ação do tuberculostático (Yamanda et al., 1985; Telenti et al., 1993; Kapur et al., 1994; Williams et al., 1994). Aproximadamente 95\% dos isolados resistentes à rifampicina têm mutações em uma região que compreende 69 pares de bases do gene $r p o B$, correspondente aos códons 511 ao 533 (Spíndola de Miranda et al., 2001).

Nos 5\% restantes, o local permanece indeterminado, com exceção de mutações já determinadas para os códons 381 (Taniguchi et al., 1996), 481 e 509 (Nasch et al., 1997) 
e 505 (Matsiota-Bernard et al., 1998). A organização estrutural e funcional da RNA polimerase está conservada entre as bactérias (Lill et al., 1975; Ovchinnikov et al., 1981). Em Escherichia coli a resistência à rifampicina também está associada com substituições específicas no gene que codifica para a subunidade $b$ da RNA polimerase (Jin, Gross, 1988). A caracterização do gene rpoB em $E$. coli demonstrou que a rifampicina interage impedindo a transcrição e que mutações no gene $r p o B$ conferem mudança conformacional no sítio de ação do fármaco, caracterizando a resistência (Jin, Gross, 1988; Miller et al., 1994). As mutações que compõem o locus rpoB têm implicações clínicas importantes, já que podem impedir a cura do doente.

\section{MÉTODOS MOLECULARES DE DETECÇÃO DE RESISTÊNCIA À RIFAMPICINA}

\section{Reação em Cadeia da Polimerase}

A técnica de reação em cadeia da polimerase (PCR) foi descrita por Saiki et al. (1985). Foi utilizada inicialmente na amplificação do gene $\beta$ globina para diagnóstico prénatal de anemia falciforme (Saiki et al., 1985; Mullis, Faloona, 1987). A introdução da enzima DNA polimerase (termoestável), obtida da bactéria Thermus aquaticus, possibilitou a automação da técnica (Saiki et al., 1988).

A PCR consiste em um método de síntese enzimática in vitro de seqüências específicas de DNA. Vários grupos de pesquisa têm apresentado propostas de estudos clínicos baseados em diferentes sistemas de PCR. Vários protocolos com diferentes iniciadores, número de ciclos e tratamento de amostras vêm sendo desenvolvidos para o diagnóstico da tuberculose (Eisenach et al., 1990). Várias metodologias têm sido propostas para o estudo da resistência do M. tuberculosis aos fármacos como SSCP-PCR, PCR Heteroduplex, INNO-LIPA e outras.

\section{SSCP PCR}

Por esta técnica pode-se detectar modificações em uma única base, através da mudança no padrão de migração de fitas simples em gel de poliacrilamida nãodesnaturante (Orita et al., 1989). O DNA amplificado é desnaturado antes de ser submetido à eletroforese. $\mathrm{O}$ padrão de migração do fragmento de DNA depende não só da massa molecular, mas também de sua conformação (estrutura secundária). Como a conformação da fita de DNA é também influenciada por sua estrutura primária, as fitas complementares migram como bandas separadas no gel e pequenas diferenças na seqüência do DNA alteram a mobilidade das fitas.
Alguns autores têm utilizado essa técnica com o intuito de estabelecer as bases moleculares da resistência de isolados de $\mathrm{Mtb}$, sendo utilizados dois controles, um do tipo sensível (S) e outro resistente (R). O fragmento de DNA de fita dupla, alvo de mutações, é desnaturado, e as duas fitas resultantes têm sua mobilidade comparada aos controles $\mathrm{R}$ e S. Os estudos correlacionaram, ainda, os dados encontrados com os testes de sensibilidade.

Com relação à utilização dessa técnica para detectar resistência em Mtb, foram demonstrados resultados favoráveis quando se utilizou a mesma em cultura de isolados de micobacterias resistentes à rifampicina, porém obtevese menos sucesso quando foi utilizado para espécimes clínicas (Telenti et al.,1997).

\section{PCR Heteroduplex}

Essa metodologia, além de ser utilizada para verificar a existência de mutações em cepas resistentes de $\mathrm{Mtb}$ (Williams et al., 1994), também tem sido utilizada para determinar polimorfismo em outros microorganismos (Delwart et al., 1993). Seqüências de DNA que apresentam alteração de pelo menos uma base podem, em gel de poliacrilamida, apresentar diferenças de migração devido a diferenças conformacionais. É necessário, inicialmente, que o fragmento de DNA seja submetido a processo de desnaturação para separação das fitas. Dois segmentos de DNA, idênticos ou não, após desnaturação são juntados em mesmo ambiente para que ocorra hibridização. Na situação de dois fragmentos não-idênticos, que apresentem diferença de pelo menos uma base, a hibridização produzirá três diferentes fitas duplas: duas formadas por fitas $100 \%$ complementares e um par de fitas não-idênticas, ou seja, um heteroduplex. Este heteroduplex, devido a alça formada no local onde ocorre o desemparelhamento da(s) base(s), deverá apresentar diferença de mobilidade. Assim, no gel, pode-se observar a presença de três bandas, sendo uma delas devido ao heteroduplex.

Pelo exposto, pode-se concluir que pelo PCR Heteroduplex o nível de informação é restrito, podendo determinar somente se existe ou não mutação (Nagamine et al., 1989; Williams et al., 1994; Leclerc et al., 1995).

Shi et al., em 2006, descreve o uso de Cromatografia líquida de Alta Eficiência em Temperatura Desnaturante (DHPLC - Denaturing high-performance liquid chromatography), como uma técnica relativamente nova, a qual utiliza a formação de heteroduplex para detectar mutações pontuais, tendo uma boa acurácia e podendo servir de rastreamento para detecção dessas mutações. 


\section{INNO-LIPA Rif TB}

Esse é um ensaio que utiliza dez sondas em um kit comercial (fitas impregnadas com nucleotídeos), chamado INNO-LIPA RIF TB (Innogenetics, Zwijndrecht, Bélgica). $\mathrm{O}$ kit detecta especificamente a resistência à rifampicina em $M$. tuberculosis, sendo que o teste consiste na amplificação por PCR de um segmento do gene $\operatorname{rpo} B$, desnaturação e hibridização dos amplicons com sondas imobilizadas em localizações conhecidas, sob condições rigidamente controladas e é baseado no princípio de hibridização de fase sólida reversa. Neste kit encontra-se uma sonda específica do complexo $M$. tuberculosis e outras nove que permitem a detecção de mutações responsáveis pela resistência da rifampicina. Cinco sondas S1, S2, S3, S4 e S5, que correspondem aos tipos selvagens (sensíveis) também são utilizadas. Se houver uma mutação em uma das cinco regiões, a sonda sensível correspondente não será hibridizada (Rossau et al., 1997).

Quatro sondas nucléicas são especialmente utilizadas para evidenciar as quatro mutações mais freqüentemente observadas no gene rpoB: R2 (D516-Val), R4a (H526Thy), R4b (H528-Asp) e R5 (531-Leu). Porém, se houver outras mutações, elas não serão detectadas (De Beenhouwer et al., 1995; Rossau et al., 1997). O teste pode ser utilizado tanto em espécimes clínicos ou cultura, é de fácil execução e o tempo para sua realização é em torno de 48 horas, porém seu custo é elevado.

Um outro tipo de sonda também disponível comercialmente, a GenoType MTBDR (Genotype MTBDR; Hain Life-science, Nehren, Germany), tem sido utilizada para detectar mutações que conferem resistência à rifampicina (Hillemann et al., 2005). Em 2006, Makinen et al. demonstraram em um estudo comparativo que tanto o INNO-LIPA RIF TB quanto o GenoType MTBDR são úteis para estudar isolados de $M t b$ em pacientes com suspeita de serem portadores de $M t b$ multi-resistente a fármacos, porém, o GenoType MTBDR apresenta a vantagem de ser capaz de detectar resistência à isoniazida e à rifampicina simultaneamente.

\section{LSSP PCR}

Em 1994, uma nova técnica, baseada na PCR, foi desenvolvida com a finalidade de detectar uma ou múltiplas mutações em um fragmento de DNA, a PCR de baixa estringência, utilizando um único iniciador, LSSP-PCR Low Stringency Single Specific Primer Polymerase Chain Reaction (Pena et al., 1994). Essa metodologia vem sendo utilizada por vários pesquisadores como ferramenta para estudar polimorfismos entre diferentes microorganismos
(Villa et al., 1995; Vago et al., 1996; Gomes et al., 1997; Lages-Silva et al., 2002; Oliveira et al., 2003). Na LSSPPCR amplifica-se inicialmente o segmento gênico que se deseja avaliar o polimorfismo. Este fragmento amplificado é purificado e submetido à nova PCR usando-se geralmente um dos iniciadores que o gerou, em condições de baixa estringência. Os amplicons produzidos na segunda PCR geram um perfil de bandas típico do fragmento em questão. Este perfil é tão complexo e individual que modificações em um único par de bases pode ser detectado.

Carvalho et al. (2003) utilizaram essa técnica pela primeira vez para estudar mutações no gene $r p o B$, mutações estas que podem conferir resistência à rifampicina. A técnica mostrou-se promissora, gerando um perfil de bandas único para as cepas sensíveis diferente dos outros gerados para aquelas resistentes.

A conduta terapêutica para cepas MDR, como também o controle da disseminação depende do pronto diagnóstico dos pacientes suspeitos. Muitas são as técnicas de PCR disponíveis para serem padronizadas ou mesmo otimizadas para o diagnóstico de cepas de M. tuberculosis resistentes. Há perspectivas reais para o uso dessas técnicas moleculares na rotina dos laboratórios de análises clínicas, o que poderá reduzir o tempo para a obtenção da informação referente à sensibilidade das cepas de $M$. tuberculosis e, assim, auxiliar na escolha de uma terapia adequada para o tratamento da doença.

\section{ABSTRACT \\ Diagnostic of rifampicin-resistance of Mycobacterium tuberculosis by polymerase chain reaction}

The resistance of Mycobacterium tuberculosis to tuberculostatic drugs has emerged as a major public health threat. The resistance to rifampicin which has been attributed to structural changes in RNA polymerase can be considered as a marker for multi-drug-resistance to tuberculosis (MDR-TB). Patients bearing rifampicinresistant strains have poor diagnosis even with treatment. Conventional culture-based drug sensibility testing can require several weeks due to the growth. In this paper we describe the most common PCR-based methods for detection of mutations that lead to rifampicin resistance, such as Single-Strand Conformation Polymorphism (SSCP), PCR Heteroduplex and INNO-LIPA. Recently, by Low Stringency using a Single Specific Primer (LSSP) assay, it was standardized a protocol that showed to be rapid and sensitive for the detection of mutations in the rpoB gene. 
UNITERMS: Mycobacterium tuberculosis. Resistance. Rifampicin. PCR

\section{REFERÊNCIAS BIBLIOGRÁFICAS}

BEMER, P.; PALICOVA, F.; RUSCH-GERDES, S.; DRUGEON, H.B.; PFYFFER, G.E. Multicentre evaluation of fully automatic BACTEC mycobacteria growth indicator tube 960 system for susceptility testing of Mycobacterium tuberculosis. J. Clin. Microbiol., v. 40, p. 150-154, 2002.

BRASIL. Ministério da Saúde. Fundação Nacional de Saúde. Centro de Referência Professor Hélio Fraga. Sociedade Brasileira de Pneumologia e Tisiologia. Controle da tuberculose: uma proposta de integração Ensino-Serviço. 5. ed. Rio de Janeiro: FUNASA/CRPHF/SBPT, 2002. $236 \mathrm{p}$.

BRUNELLO, F.; FONTANA, R.; Reliablity of the MBBactT system for testing susceptility of Mycobacterium tuberculosis complex strains to anti-tuberculous drugs. $J$. Clin. Microbiol., v. 38, p. 872-873, 2000.

CARVALHO, W.S.; SPINDOLA DE MIRANDA, S.; COSTA, K.M.; ARAUJO, J.G.V.C.; AUGUSTO, C.J.; PESQUERO, J.B.; PESQUERO, J.L.; GOMES, M.A. Low-stringency single-specific-primer PCR as a tool for detection of mutations in the rpoB gene of rifampinresistant Mycobacterium tuberculosis. J. Clin. Microbiol., v. 41, p. 3384-3386, 2003.

COOKSEY, R.C.; MORLOCK, G.P.; GLICKMAN, S.; CRAWFORD, J.T. Evaluation of a line probe assay kit for characterization of $r p o B$ mutations in rifampin-resistant Mycobacterium tuberculosis isolates from patients in New York City. J. Clin. Microbiol., v. 35, p. 1281-1283, 1997.

DE BEENHOUWER, H.; LHIANG, Z.; JANNES, G.; MIJS, W.; MACHTELINCKX, L.;ROSSAU,R.; TRAORE, H., PORTAELS, F. Rapid detection of rifampicin resistance in sputum and biopsy specimens from tuberculosis patients by PCR and line probe assay. Tubercle Lung Dis., v. 76, p. 425-430, 1995.

DELWART, E.L.; SHEPAER, E.G.; LOUWAGIE, J.; McCUTCHAN, F.E.; GREZ, M., WAIGMANN, H.R.; MULLINS, J.I. Genetic relationships determined by a DNA heteroduplex mobility assay: Analysis of HIV-1 env genes. Science, v. 262, p. 1257-1261, 1993.
DROBNIEWSKI, F.A. Is death inevitable with multiresistant TB plus HIV infection? Lancet, v. 349, p. 71-72, 1997.

EISENACH, K.D.; CAVE, M.D.; BATES, J.H.; CRAWFORD, J.T. Polymerase Chain Reaction Amplification of a Repetitive DNA Sequence Specific for Mycobacterium tuberculosis. J. Infect. Dis., v. 161, p. $977-981,1990$.

FISCHL, M.; DAIKOS, G.; UTTAMCHANDANI, R. Clinical presentation and outcome of patients with HIV infection and tuberculosis caused by multiple-drugresistant bacilli. Ann. Intern. Med., v. 117, p. 184-190, 1992.

FIUZA DE MELO, F. A. Tuberculose. In: VERONESI, R., FOCACCIA, R. Tratado de Infectologia. São Paulo: Editora Atheneu, 1997. v. 1, cap. 74, p. 914-959.

FRIEDEN, T.R.; STERLING, T.; PABLOS-MENDEZ, A.; KILBURN, J.O.; DOOLEY, S.W. The emergence of drug-resistant tuberculosis in New York City. N. Engl.J. Med., v. 328, p. 521-526, 1993.

GOMES, M.A.; SILVA, E.F.; MACEDO, A.M.; VAGO, A.R.; MELO, M.N. LSSP-PCR for characterization of strains of Entamoeba histolytica isolated in Brazil. Parasitology, v. 114, p. 517-520, 1997.

HILLEMAN, D.; WEIZENEGGER, M.; KUBICA, T.; RICHTER, E.; NIEMANN, S. Use of the Genotype MTBDR assay for rapid detection of rifampin and isoniazid resistence in Mycobacterium tuberculosis complex isolates. J. Clin. Microbiol., v. 43, n. 8, p. 3699 703, 2005.

ISEMAN, M.D. Treatment of multidrug-resistant tuberculosis. N. Engl. J. Med., v. 329, p. 784-791, 1993.

ISEMAN, M.D. Evolution of drug-resistant tuberculosis: a tale of two species. Proc. Natl. Acad. Sci., v. 91, p. 24282429, 1994.

JIN D.J.; GROSS C.A. Mapping and sequencing of mutations in the Escherichia coli rpoB gene that lead to rifampicin resistance. J. Mol. Biol., v. 202, p. 45-48, 1988.

KAKKAR N.; SHARMA M.; RAY P.; SETH S.; KUMAR S. Evaluation of E-test for susceptility testing of mycobacteria to primary antitubercular drugs. Indian J. Med. Res., v.111, p.168-171, 2000. 
KAPUR, V.; LI, L.L.; IORDANESCU, S.; HAMRICK, M.R.; WANGER, A.; KREISWIRTH, B.N.; MUSSER, J.M. Characterization by automated DNA sequencing of mutations in the gene (rpoB) encoding the RNA polymerase $B$ subunit in rifampin - resistant Mycobacterium tuberculosis strains from New York City and Texas. J. Clin. Microbiol., v. 32, p. 1095-1098, 1994.

KATOCH, V.M. Newer diagnostic techniques for tuberculosis. Indian J. Med. Res., v. 120, p. 418-428, 2004.

KIRK SM. ; SCHELL RF. ; MOORE AV. ; CALLISTER SM. ; MAZUREK GH. Flow cytometric testing of susceptilities of Mycobacterium tuberculosis isolates to ethambutol, isoniazid and rifampicin in 24 hours. J. Clin. Microbiol., v.36, p. 1568-1571, 1998.

KRISHNAMURTHY A. ; RODRIGUES C. ; MEHTA AP. Rapid detection of rifampicin resistance in Mycobacterium tuberculosis by phage assay. Indian J. Med. Microbiol., v. 20, p. 211-214, 2002.

LAJES-SILVA, E.; RAMIREZ, L.E.; SILVA-VERGARA, M.L.; CHIARI, E. Chagasic meningoencephalitis in a patient with acquired immunodeficiency syndrome: diagnosis, follow-up, and genetic characterization of Trypanosoma cruzi. Clin. Infect. Dis., v. 34, p. 118-123, 2002.

LECLERC, H.;GAILLARD, J-L.; SIMONET, M. La bactérie et le monde bactérien. In:_ Microbiologie medicale, Paris: s.c.p., 1995. 535p.

LEE C.N.; HEIFETS, B. Determination of minimal inhibitory concentrations of antituberculosis drugs by radiometric and conventional methods. Am. Rev. Respir. Dis., v. 136, p. 349-352, 1987.

LILL, U.I.; BEHRENDT, E.M.; HARTMANN, G.R. Hybridization in vitro of subunits of the DNA-dependent RNA polymerase from Escherichia coli and Micrococcus luteus. Eur. J. Biochem., v. 52, p. 411-420, 1975.

MAGGI, N.; PASQUALUCCI, C.R.; BALLOTTA, R.; SENSI, P. Rifampicin: a new orally active rifamycin. Chemotherapy, v. 11, p. 285-92, 1966.
MAKINEN J, MARTTILA HJ, MARJAMAKI M, VILJANEN MK, SOINI, H. Comparison of two commercially available DNA line probe assays for detection of multidrug-resistant Mycobacterium tuberculosis. J. Clin. Microbiol.,v. 44, n. 2, p. 350-352, 2006.

MATSIOTA-BERNARD, P.; VRIONI, G.; MARINIS, E. Characterization of $r p o B$ mutations in rifampin-resistant Clinical Mycobacterium tuberculosis isolates from Greece. J. Clin. Microbiol., v. 36, p. 20-23, 1998.

MILLER, L.P.; CRAWFORD, J.T.; SHINNICK, T.M. The rpoB gene of Mycobacterium tuberculosis. Antimicrob. Agents Chemother., v. 38, p. 805-811, 1994.

MITCHISON, D.; NUNN, A. A influence of initial drug resistance on the response to short-course chemotherapy of pulmonary tuberculosis. Am. Rev. Respir. Dis., v. 133, p. 423-430, 1986.

MULLIS, K.B.; FALOONA, F.A. Specific Synthesis ofDNA in vitro via a Polymerase-catalyzed Chain Reaction. Methods Enzymol., v. 155, p. 335, 1987.

MURRAY, C.J.L.; STYBLO, K.; ROUILLON, A. Tuberculosis in developing countries: burden, intervention and cost. Bull. Int. Un. Tuberc. Lung Dis., v. 65, p. 6-24, 1990.

NAGAMINE, C.M.; CHAN, K.; LAU, Y.F. A PCR artifact: generation of heteroduplexes. Am. J. Hum. Genet., v. 45, p. 337-339, 1989.

NASH, K.A.; GAYTAN, A.; INDERLIED, C.B. Detection of rifampin resistance in Mycobacterium tuberculosis by use of a rapid, simple, and specific RNA/RNA mismatch assay. J. Infect Dis., v. 176, p. 533-536, 1997.

OLIVEIRA, M.A.A.; CABALLERO, O.L.; VAGO, A.R.; HARSKEERL, R.A; ROMANHA, A.J.; PENA, S.D.J.; SIMPSON, A.J.G.; KOURY, M.C. Low-stringency single specific primer PCR for identification of Leptospira. $J$. Med. Microbiol., v. 52, p. 127-135, 2003.

ORITA, M.; IWAHANA, H.; KANAZAWA, H.; HAYASHI, K.; SEKIYA, T. Detection of polymorphisms of human DNA by gel electrophoresis as single-strand conformation polymorphisms. Proc. Natl. Acad. Sci. USA., v. 86, p. 2766-2770, 1989. 
OVCHINNIKOV, Y.A.; MONASTYRSKAYA, G.S.; GUBANOV, V.V.; GURGEY, S.O.; CHERTOV, O.Y., MODYANOV, N.N.; GRINKEVICH, U.A.; MAKAROVA, I.A.; MARCHENKO, T.V.; POLOVNIKOVA, I.N.; LIPKIN, V.M.; SVERDLOV, E.D. The primary struture of Escherichia coli RNA polymerase. Nucleotide sequence of the $r p o B$ gene and amino-acid sequence of the $B$-subunit. Eur. J. Biochem., v. 116, p. 621-629, 1981.

PENA, S.D.J.; BARRETO, G.; VAGO, A.R.; DE MARCO, L.; REINACH, F.C.; DIAS NETO, E.; SIMPSON, A.J.G. Sequence-specific "gene signatures" can be obtained by PCR with single specific primers at low stringency. Proc. Natl. Acad. Sci. USA., v. 91, p. 19461949, 1994.

RIEDER, H.L. Interventions for tuberculosis control and elimination. Paris: International Union Against Tuberculosis and Lung Disease (IUATLD), 2002.249 p.

RISKA, P.F.; SU Y.; BARDAROV, S.; FREUNDLICH, L.; SARKIS, G.; HATFULL, G.; CARRIÈRE, C.; KUMAR, V.; CHAN, J.; JACOBS J.R., W.R. Rapid film-based determination of antibiotic susceptibilies of Mycobacterium tuberculosis strains by using a luciferase reporter phage and the Bronx box. J. Clin. Microbiol., v. 37, p. 1144-1149, 1999.

ROBERTS, G.D.; KONEMAN, E.W.; KIM, Y.K. Mycobacterium. In: Ballows, A.; HAUSLER, W.J.; HERRMAN, K.L.; EISENBERG, H.D.; SHADOMY, H.J. (Eds.). Manual of clinical microbiology. 5. ed, Washington: American Society for Microbiology, 1991.p. 304-340.

ROSSAU, R.; TRAORE, H.; DE BEENHOUWER, H.; MIJK, O.; JANNES, G.; DE RIJK, P.; PORTAELS, E. Evaluation of the INNO-LiPA-RIF. TB assay a reverse hybridization assay for the simultaneous detection of Mycobacterium tuberculosis complex and its resistance to rifampin. Antimicrob. Agents Chemother., v.41, n.10, p.2093-2098, 1997.

SAIKI, R.K.; SCHARF, S.; FALOONA, F.; MULLIS, K.B.; HORN, G.T.; ERLICH, H.A.; ARNHEIM, N. Enzymatic amplification of b-globulin genomic sequences and restriction site analysis for diagnosis of sickle cell anemia. Science, v. 230, p. 1350-1354, 1985.
SAIKI, R.K.; GELFAND, D.H.; STOFFEL, S.; SCHARF, S.J.; HIGUCHI, R.; HORN, G.T.; MULLIS, K.B.; ERLICH, H.A. Primer-directed enzymatic amplification of DNA with a thermostable DNA polymerase. Science, v. 239, p. 487-491, 1988.

SHI, R. ; OTOMO, K. ; YAMANDA, H. ; TATSUMI, T. ; SUGAWARA, I. Temperature-mediated heteroduplex analysis for the detection of drug-resistant gene mutations in clinical isolation of Mycobacterium tuberculosis by denaturing HPLC, SURVEYOR nuclease. Microbes Infect., v. 8, p. 128-135, 2006.

SNIDER, D.E. Jr.; ROPER, W.L. The new tuberculosis. $N$. Engl. J. Med., v. 326, p. 703-705, 1992.

SPINDOLA DE MIRANDA S.; KRITSKI, A.L.; FILLIOL, I.; MABILAT, C.; PANTEIX, G.; DROUET, E. Mutations in the $\operatorname{rpo} B$ gene of rifampicin-resistant Mycobacterium tuberculosis strains isolated in Brazil and France. Mem. Inst. Oswaldo Cruz, v. 96, p. 247-250, 2001.

TANIGUCHI, H.; ARAMAKI, H.; NIKAIDI, Y.; MIZUGUCHI, Y.; NAKAMURA, M.; KOGA, T.; YOSHIDA, S. Rifampicin resistance and mutation of the rpoB gene in Mycobacterium tuberculosis. FEMS Microbiol. Lett., v. 144, p. 103-108, 1996.

TELENTI, A.; IMBODEN, P.; MARCHESI, F.; LOWRIE, D.; COLE, S.; COLSTON, M.J.; MATTER, L.; SCHOPFER, K.; BODMER, T. Detection of rifampicinresistance mutations in Mycobacterium tuberculosis. Lancet, v. 341, p. 647-650, 1993.

TELENTI, A.; HONORÉ, N.; BERNASCONI, C.; MARCH, J.; ORTEGA, A.; HEYM,B.; TAKKIFF, H.E.; COLE, S.T. Genotipic assessment of isoniazid and rifampin resistance in Mycobacterium tuberculosis: a blind study at reference laboratory level. J. Clin. Microbiol., v. 35, p. 719-723, 1997.

TORTOLI, E.; CICHERO, P.; PIERSIMONI, C.; SIMONETTI, T.; GESU, G.; NISTTA, D. Use of BACTEC MGIT for recovery of mycobacteria from clinical specimens: multicentric study. J. Clin. Microbiol., v. 37, p. 3578-3582, 1999. 
VAGO, A.R.; MACEDO, A.M.; OLIVEIRA, R.P.; ANDRADE, L.O.; CHIARI, E.; GALVÃO, L.M.C.; SIMPSON, A.J.G.; TOSTES, S.; PENA, S.D.J. Kinetoplast DNA signatures of Trypanosoma cruzi strains obtained directly from infected tissues. Am. J. Pathol., v. 149, p. 2153-2159, 1996.

VILLA, L.L.; CABARELLO, O.L.; LEVI, J.E.; PENA, S.D.J.; SIMPSON, A.J.G. An approach to human papilomavirus identification using low stringency single specific primer PCR. Mol. Cel. Probes., v. 9, p. 45-48, 1995.

WATTERSON, S.A.; WILSON, S.M.; YATES, M.D.; DROBNIEWSKI, F.A. Comparison of three molecular assays for rapid detection of rifampin resistance in Mycobacterium tuberculosis. J. Clin. Microbiol., v. 36, p. 1969-1973, 1998.

WILLIAMS, L.D.; WAGUESPACK, C.; EISENACH K.; CRAWFORD, J.T.; PORTAELS, F.; SALFINGER, M.; NOLAN, C.M.; ABE, C.; STICHT-FROH, V.; GILLIS, T.P. Characterization of rifampin resistance in pathogenic Mycobacteria. Antimicrob. Agents Chemother., v. 38, p. 2380-2386, 1994.
WILSON, S.; AL-SUWAIDI, A.; MCNERNY, R.; PORTER, J.; DROBNIEWSKI, F. Evaluation of a new rapid bacteriophage based method for the drug susceptibility testing of Mycobacterium tuberculosis. Nature Med., v. 3, p. 415-418, 1997.

WORLD HEALTH ORGANIZATION. Global tuberculosis control. Annual report. Geneva, 2005. 258p.

YAMANDA, T.; NAGATA, A.; ONO, Y.; SUZUKI, Y.; YAMANOUCHI, T. Alteration of ribosomes and RNA polymerase in drug-resistant clinical isolates of Mycobacterium tuberculosis. Antimicrob. Agents Chemother., v. 27, p. 921-924, 1985.

Recebido para publicação em 18 de outubro de 2005. Aceito para publicação em 29 de março de 2007. 